\title{
Investigating Suggestions for Increasing the Throughput Rate of IS Students
}

\author{
Elsa Naudé and Tertia Hörne \\ University of South Africa, Pretoria, South Africa
}

\author{
naudeej@unisa.ac.za hornet@unisa.ac.za
}

\begin{abstract}
During the past few years science faculties at tertiary education institutions in South Africa have had to face increasing pressure from national as well as provincial government bodies to improve the student throughput rate. Various suggestions have been made to achieve this goal. This paper investigates the viability of two of these suggestions for solving the throughput problem. It is part of a larger reflexive research project investigating various aspects of the teaching and learning of Computing and IS through distance education. Information from the assignment records and the examination marks of students for a specific Computer Science second year module with a practical component was used for this study.
\end{abstract}

Keywords: Education, programming, assignments, pass rate, distance education

\section{Introduction}

During the last few years science faculties at tertiary education institutions in South Africa have had to face increasing pressure from national as well as provincial government bodies to improve the student throughput rate. At the University of South Africa (Unisa) various sugge stions have been made to achieve this goal (Unisa Faculty Executive, 2001). One suggestion was that students who failed the examination, but obtained a mark of at least $30 \%$, be allowed to sit for a supplementary examination. A decision to this effect was taken at a Unisa Science Faculty board meeting. Another possibility is to give all students automatic admission to the examination, regardless of whether any assignments were submitted, or visual proof exists, that a particular student did in fact spend time doing preparatory work for the examination. Since go vernment subsidies are allocated on the basis of the pass rate of a module and not only on the number of students that are registered for the module, this affects all Departments at tertiary institutions.

We believe that the onus is on the lecturers of subjects with relatively low pass rates, such as Computer Science subjects in our case, to put measures in place to improve the situation without lowering standards. In this study we investigated the viability of the suggestions mentioned above for solving the throughput problem of distance learners.

In the next sections we discuss the specific research questions that we considered and the methodology used for the study. Then we describe the results of the study regarding the examination results of different groups of students. We also provide statistics regarding the pass rate of students who sat for the sup-

Material published as part of these proceedings, either on-line or in print, is copyrighted by Informing Science. Permission to make digital or paper copy of part or all of these works for personal or classroom use is granted without fee provided that the copies are not made or distributed for profit or commercial advantage AND that copies 1) bear this notice in full and 2) give the full citation on the first page. It is permissible to abstract these works so long as credit is given. To copy in all other cases or to republish or to post on a server or to redistribute to lists requires specific permission from the publisher at Publisher@InformingScience.org plementary examination. Finally, we briefly discuss further research issues pertaining to the throughput rate of Computer Science students as well as that of university students in ge neral.

\section{Research Questions}

In the Department of Computer Science and Information Systems at Unisa students have to ob- 
tain admission to the October/November examination by earning credits throughout the academic year. Credits are earned by submitting assignments. For this study we concentrated on a second year Computer Science module in computer organisation, with a practical component comprising assembly language programming. There were a total of four assignments that the students could submit for a maximum of 200 credits. A student had to get a total of 100 credits to obtain automatic admission to the examination. It is important to note that the total number of credits that a student obtains for assignments is not taken into account when the final mark for the student is calc ulated.

We have always believed that assignments play an important role in preparing students for the examination in any module containing a practical programming component. Thus we were particularly interested to see how students who did not qualify for examination admission by earning enough credits but were granted admission to the examination, would fare in the examination compared to students who obtained admis sion through submitting assignments.

The hypothesis was formulated as follows:

\section{$\mathrm{H}_{0}$ : There is no significant difference between the results of students who were granted examina- tion admission compared to students who obtained examination admission.}

We also wanted to see if students who failed, i.e. got less than $50 \%$, and obtained marks between $30 \%$ and $39 \%$ in the examination in October/November, have a realistic chance of passing a suppleme ntary examination in January. We compared this group to the group of students who failed but obtained marks of between $40 \%$ and $49 \%$.

The hypothesis was formulated as follows:

$\mathbf{H}_{0}$ : There is no significant difference between the supplementary examination results of students who obtained between $30 \%$ and $39 \%$ in the original examination and those students who obtained between $40 \%$ and $49 \%$.

\section{Methodology and Results}

Two sets of data were analysed: the data for 2000/2001, and the data for 2001/2002. The number of students registered for this module was 438 and 321, for 2000 and 2001 respectively, and the number of students who got admission to the examination was about 250 in both cases.

\section{Admission to the Examination}

There were a total of four assignments (one self-assessment, two multiple choice and one written assignment) that the students could submit for a maximum of 200 credits. A student had to get a total of 100 credits to obtain admission to the examination, although we eventually granted admission to all students with 80 or more credits. There were a few special cases with less than 80 credits that were also granted admission.

As described above, the types of assignment for the module studied are mixed which should promote the effectiveness of the learning process (Brown, 1997). This approach also provides flexibility of assessment, the advantages of which are discussed in (Allsopp, 2002).

We provide detailed discussions of each of the assignments in the form of tutorial letters. The primary aim of the assignments is to help students to work through the syllabus at a steady pace. According to Courts \& McInerney (1993), assessment of any kind that is not directed at improving the lectures (which would be the study material in our case) is a waste of money and time. For this reason, we pay particular attention to providing additional explanations on topics that the students find relatively difficult in order to improve our teaching of the subject (Sims, 1992). These topics are identified by studying the assignment attempts submitted by individual students. 
Naudé \& Hörne

\begin{tabular}{|c|c|c|c|c|c|c|}
\hline $\begin{array}{l}\text { Credit } \\
\text { Range }\end{array}$ & \begin{tabular}{c|} 
No of \\
Students (2000)
\end{tabular} & $\begin{array}{l}\text { Passed } \\
(2000)\end{array}$ & $\begin{array}{c}\text { \% Passed } \\
(2000)\end{array}$ & $\begin{array}{c}\text { No of students } \\
(2001)\end{array}$ & $\begin{array}{c}\text { Passed } \\
(2001)\end{array}$ & $\begin{array}{c}\text { \% Passed } \\
(2001)\end{array}$ \\
\hline$<80$ & 4 & 1 & 25.0 & 2 & 1 & 50.0 \\
\hline $80-89$ & 10 & 4 & 40.0 & 5 & 2 & 40.0 \\
\hline $90-99$ & 9 & 1 & 11.1 & 12 & 6 & 50.0 \\
\hline $100-109$ & 31 & 11 & 35.5 & 43 & 29 & 67.4 \\
\hline $110-119$ & 34 & 18 & 52.9 & 41 & 25 & 61.0 \\
\hline $120-129$ & 22 & 13 & 59.1 & 31 & 26 & 83.9 \\
\hline $130-139$ & 32 & 18 & 56.3 & 21 & 14 & 66.7 \\
\hline $140-149$ & 26 & 22 & 84.6 & 21 & 17 & 81.0 \\
\hline $150-159$ & 16 & 13 & 81.3 & 22 & 21 & 95.5 \\
\hline $160-169$ & 9 & 8 & 88.9 & 3 & 3 & 100.0 \\
\hline $170-179$ & 10 & 10 & 100.0 & 5 & 5 & 100.0 \\
\hline $180-189$ & 14 & 14 & 100.0 & 10 & 10 & 100.0 \\
\hline$>189$ & 4 & 4 & 100.0 & 3 & 3 & 100.0 \\
\hline & 221 & 137 & 62.0 & 219 & 162 & 74.0 \\
\hline
\end{tabular}

Table 1: Pass rates within credit ranges

Table 1 indicates the relationship between the pass rate of students and the number of credits obtained for admission to the examination.

This information is reflected in the Figure 1 that represents the information for the year 2000 and the year 2001 respectively.

It is clear from the graph in Figure 1 that the higher the number of credits obtained, the higher the pass rate.

In order to do a statistical test on the data contained in Table 1, it can be summarised as shown in Table 2 and Table 3, where Group A represents the students that obtained automatic admission to the examination, and Group B represents the students that were granted special admission to the examination.

The data was analysed using a $\chi^{2}$-test of independence to determine whether there is in fact a significant difference between the results of the two groups, Group A and Group B.

Based on Table 2, $\chi^{2}(1, \mathrm{~N}=221)=14.05$, which is much larger than the corresponding test statistic $\chi_{0.001}^{2}=10.83$. 


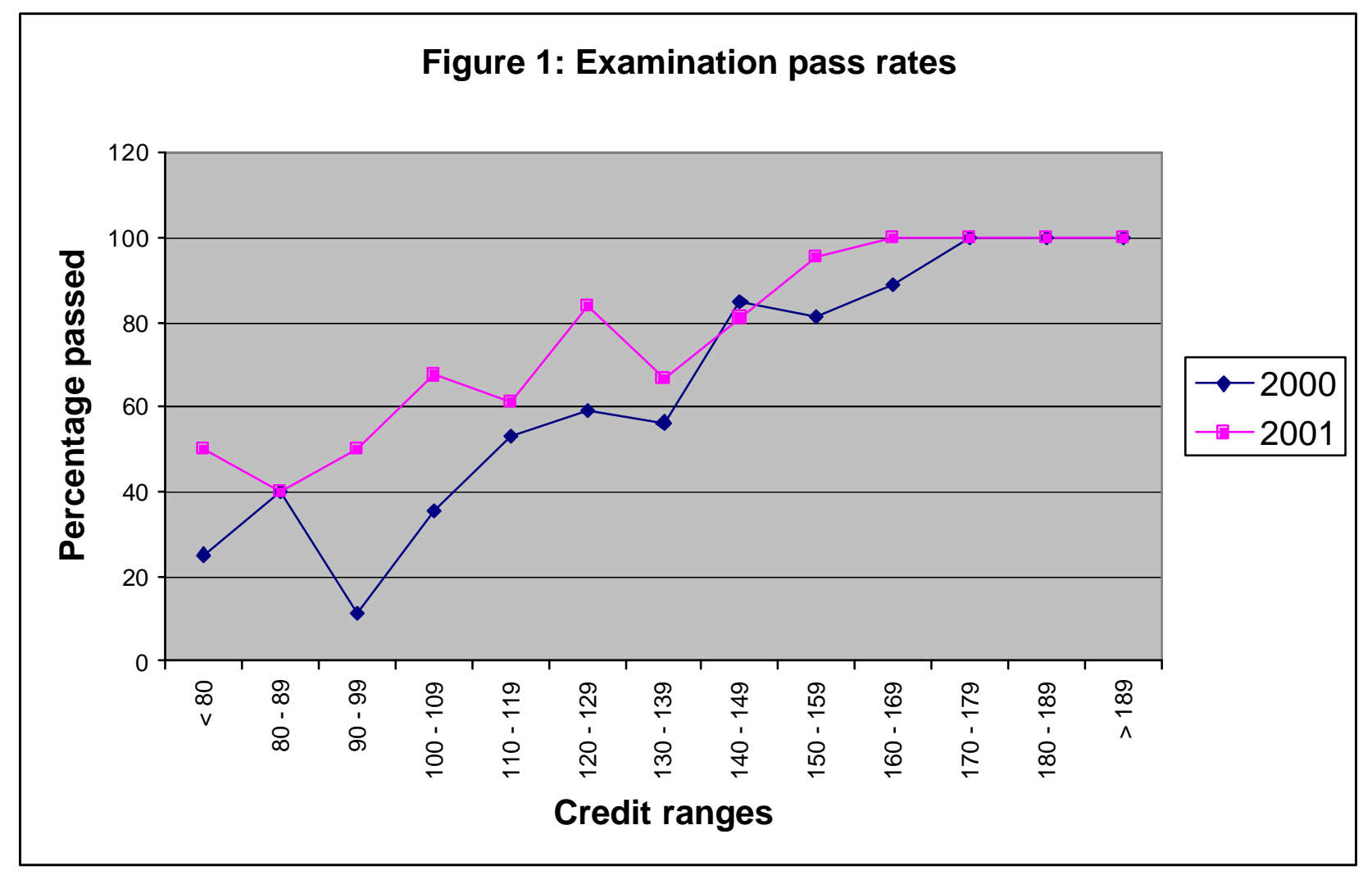

For Table $3, \chi^{2}(1, \mathrm{~N}=219)=4.92$, which is larger than $\chi_{0.05}^{2}=3.84$. Although the data for 2001 is less conclusive than that of 2000 , ind $\mathrm{i}-$ cations are that the re is a significant difference in the proportions of students from Group A vs. Group B that passed.

Based on these results we could reject $\mathrm{H}_{0}$, which states that there is not a significant difference between the results of students who were granted examination admission compared to those students who obtained automatic examination admission. This is consistent with our theory that the submission of assignments increases a student's chances of passing. The assignments include active as well as experiential learning tasks as is advocated by Cope (2002). Indications are that the probability of deep

\begin{tabular}{|l|l|l|l|}
\hline & $\begin{array}{l}\text { Obtained } \\
\text { Group A }\end{array}$ & $\begin{array}{l}\text { Granted } \\
\text { Group B }\end{array}$ & Total \\
\hline Passed & $131(66 \%)$ & $6(26 \%)$ & $\mathbf{1 3 7}$ \\
\hline Failed & 67 & 17 & $\mathbf{8 4}$ \\
\hline Total & $\mathbf{1 9 8}(\mathbf{1 0 0 \% )}$ & $\mathbf{2 3 ( 1 0 0 \% )}$ & $\mathbf{2 2 1}$ \\
\hline
\end{tabular}

Table 2: 2000 Admission obtained/granted

\begin{tabular}{|l|l|l|l|}
\hline & $\begin{array}{l}\text { Obtained } \\
\text { Group A }\end{array}$ & $\begin{array}{l}\text { Granted } \\
\text { Group B }\end{array}$ & Total \\
\hline Passed & $152(76 \%)$ & $10(53 \%)$ & $\mathbf{1 6 2}$ \\
\hline Failed & 48 & 9 & $\mathbf{5 7}$ \\
\hline Total & $\mathbf{2 0 0}(\mathbf{1 0 0 \%})$ & $\mathbf{1 9}(\mathbf{1 0 0 \%})$ & $\mathbf{2 1 9}$ \\
\hline
\end{tabular}

Table 3: 2001 Admission obtained/granted learning being achieved is significantly higher for students who submit fair attempts at all the assignments set for this particular course than for students that do not put in enough effort during the course of the academic year. This is also supported by the research of Box (2002) who found that the more work a student does for a specific course during the relevant academic period, the better the final examination results of that particular student will be.

However, causality could not be proven due to the relatively small number of students meeting the requirements for such a study (that is students who were granted examination admission and failed the 
examination in one year, then obtained examination admission the subsequent year). Specific measures to ensure a larger sample are necessary.

Various factors could have had an influence on the results of this study.

1. An interesting tendency we noticed was that there are quite a number of good students who only work until they know that they have admission to the examination and did typically not submit the last assignment. This suspicion is supported by the fact that, from the 43 students that got distinctions in the Oct/Nov 2000 examination, there were 22 (that is 51\%) who submitted only 3 assignments. We suspect that this will not easily happen at residential universities where the yearmark frequently forms a significant portion of the final mark for a student. This means that students who work for a distinction will do all the assignments to ensure that the year-mark is as high as possible.

2. Students work in groups and, although it is not allowed, it frequently happens that all the students from one group submit identical assignments. This means that it may happen that a partic ular student has good credits but has not mastered the study material, so will not be able to pass the examination.

3. There are quite a number of students that repeat the module, so may have partially mastered the study material in a previous year. For the 2001 group, for example, 172 of the 321 registered students $(54 \%)$ were repeaters. One of these was repeating the module for the $8^{\text {th }}$ time, and two for the $7^{\text {th }}$ time.

To take this experiment a bit further, we also conducted the following study for the 2000/2001 group of students: One of the assignments the students had to submit was a relatively simple program in assembly language that tested most of the programming aspects that form part of the syllabus. The assignment was not compulsory but could be regarded as a small project. The students had to submit the executable program, which could then be tested on a PC. Detailed feedback is given on the programming effort of each student. According to Tane nbaum (1999), doing some programming in an assembly language leads to a better understanding of the theoretical aspects of computer organisation. We wanted to establish what the probability is of a student passing the examination if there is no indication that he/she mastered the practical component of the study material as was tested in this particular assignment.

Our findings were as follows: The proportion of students that passed this assignment and also passed the examination was $79 \%$. The proportion of students that passed this assignment and also passed the theoretical part of the examination paper was $72 \%$, and the proportion of students that passed this assignment and also passed the practical part of the examination paper was also $72 \%$. It seems that this particular assignment contributed to the success of quite a high percentage of students. The results of this study also seem to support the findings of Brown (1997) that proper feedback, as was given in this case, augments the learning process of students.

\section{Automatic Admission to Supplementary Examination}

We used the results from the supplementary examinations in January/February to test the second hypothesis. The following two tables (Tables 4 and 5) give the results of students that failed during the October/November examinations and were granted admission to the supplementary examination in January. We divided the students into two groups: those who obtained a mark in the range $30-39$ (Group C), and those who obtained a mark in the range $40-49$ (Group D). In this case, we were interested to know whether there is a significant difference in the respective pass rates for these two groups. 
Although there is a notable difference between the pass rates of the two groups for $2001 / 2002$ (62\% vs. $36 \%$ ), it is statistically not significant $\chi^{2}(1$, $\mathrm{N}=32)$ = 1.89). This is probably due to $\mathrm{N}$ being small. The slightly larger $\mathrm{N}$ (46) for the 2000/2001 supplementary examination, results in a small increase in the value of $\chi^{2}$ (3.42), which is only significant on $\alpha=0.01$. Thus the hypothesis could only be rejected based on the 2000/2001 results but not on the 2001/2002 results. Although the results do not provide us with conclusive evidence of the futility of allowing students with less than $40 \%$ to sit for the supplementary examinations, a further study involving a larger number of students could provide such evidence. However, other factors such as cost to the university, and the much higher proportion of absenteeism in Group C of both yeargroups, should also be considered when decisions in this regard are made.

\begin{tabular}{|l|c|c|c|}
\hline & $\begin{array}{c}\text { Group C: Mark in } \\
\text { Oct/Nov in the } \\
\text { range } 30-39 \%\end{array}$ & $\begin{array}{c}\text { Group D: Mark in } \\
\text { Oct/Nov in the } \\
\text { range 40-49\% }\end{array}$ & Total \\
\hline Passed & $6(32 \%)$ & $16(59 \%)$ & $\mathbf{2 2}$ \\
\hline Failed & 13 & 11 & $\mathbf{2 4}$ \\
\hline Total & $\mathbf{1 9}$ & $\mathbf{2 7}$ & $\mathbf{4 6}$ \\
\hline
\end{tabular}

Table 4: 2000/2001 - Examination/Supplementary Examination results

(Note: The total number of students from group $\mathrm{C}$ absent from the examination $=13(41 \%)$. The total number of students from group D absent from the examination $=8(23 \%)$.)

\begin{tabular}{|l|c|c|c|}
\hline & $\begin{array}{c}\text { Group C: Mark in } \\
\text { Oct/Nov in the } \\
\text { range 30-39\% }\end{array}$ & $\begin{array}{c}\text { Group D: Mark in } \\
\text { Oct/Nov in the } \\
\text { range 40-49\% }\end{array}$ & Total \\
\hline Passed & $4(36 \%)$ & $13(62 \%)$ & $\mathbf{1 7}$ \\
\hline Failed & 7 & 8 & $\mathbf{1 5}$ \\
\hline Total & $\mathbf{1 1}$ & $\mathbf{2 1}$ & $\mathbf{3 2}$ \\
\hline
\end{tabular}

Table 5: 2001/2002 - Examination/Supplementary Examination results

(Note: The total number of students from group $\mathrm{C}$ absent from the examination $=12(52 \%)$. The total number of students from group $\mathrm{D}$ absent from the examination $=4(16 \%)$.)

\section{Further Research}

The impact of student absenteeism should be investigated, especially in the case of students with a $30 \%$ - 39\% examination mark who are allowed to sit for the supplementary examination. The percentage of absentees for the year-end examinations for the module that was used in this study is also relatively high. In the October/November 2000 examination, 17\% of students that had admission were absent from the examination, and in October/November 2001 this percentage was 15\%. For a large module, such as first year IS module, that has about 3500 registered students, a large numbers of students are involved. Costs incurred involve printing of examination papers, dispatching the papers and answering books to remote parts of the country and abroad, and organising and paying for examination venues and invigilators. The financial implications may not be that significant for residential institutions, but for distance education institutions, these are certainly not negligible and should be investigated by the University.

Further research to investigate causality between assignments and examination results are planned. Specific measures to ensure a larger sample could include giving more students admission to the examination, and encouraging students to submit more assignments. We also think that the pass rate will improve if the year-mark counts toward the final mark.

Our study involved a module that is only partly practical (programming). The study will be extended to consider a purely practical (programming) module as well as a purely 'theoretical' module, e.g. Introduction to Business Information Systems. A comparison between these could support the indications that we cannot do away with examination admission requirements for programming modules. 


\section{References}

Allsopp, L. (2002). Flexibility in assessment - An evaluation of student performance. Proceedings of the IS2002 Informing Science + IT Education Conference.

Box, I. (2002). Applying educational research to improve teaching and learning in information systems. Proceedings of the IS2002 Informing Science + IT Education Conference.

Brown, G. with Bull, J. \& Pendlebury, M. (1997). Assessing student learning in higher education. Routledge, USA.

Cope, C. (2002). Seeking meaning: The educationally critical aspect of learning about information systems. Proceedings of the IS2002 Informing Science + IT Education Conference.

Courts, P.L. \& McInerney, K.H. (1993). Assessment in higher education: Politics, pedagogy, and portfolios. Praeger Publishers, USA.

University of South Africa Faculty Executive. (2001). Program mix: Faculty of Science. Agenda of special meeting of the University of South Africa, Faculty of Science, 30 July 2001.

Sims, S.J. (1992). Student outcomes assessment: A historical review and guide to program Development. Green wood Press, USA.

Tanenbaum, A.S. (1999). Structured computer organization, Fourth Edition. Prentice-Hall, USA.

\section{Biographies}

Elsa Naudé has been teaching Computer Science \& Information Systems degree courses at the University of South Africa since 1989. She also spent some time teaching Computer Studies part time to high school learners. Her main research interests are bioinformatics and everything related to the teaching and learning of information technology. She spends most of her free time training for and participating in road races and duathlons.

Tertia Hörne is a lecturer in the Department of Computer Science and Information Systems at Unisa. She has been developing and teaching courses in computer organization, logic programming and functional programming since 1992. Her research interests include IS education, program specifications for concurrent systems, applied logic, and constraint logic programming. 